DAPHNE NORONHA HACHUL

\title{
PROTEÇÃO JURÍDICA DO INVESTIDOR-CONSUMIDOR
}

\author{
Dissertação de Mestrado
}

Orientadora: Professora Associada Doutora Cíntia Rosa Pereira de Lima

UNIVERSIDADE DE SÃO PAULO

FACULDADE DE DIREITO

São Paulo-SP

2018 
DAPHNE NORONHA HACHUL

Proteção jurídica do investidor-consumidor

Dissertação apresentada à Banca Examinadora do Programa de PósGraduação em Direito, da Faculdade de Direito da Universidade de São Paulo, como exigência parcial para obtenção do título de Mestre em Direito, na área de concentração Direito Civil, sob a orientação da Professora Associada Doutora Cíntia Rosa Pereira de Lima.

UNIVERSIDADE DE SÃO PAULO

FACULDADE DE DIREITO

São Paulo-SP

2018 
Hachul, Daphne Noronha

Proteção Jurídica do Investidor-Consumidor / Daphne Noronha Hachul; orientadora Cíntia Rosa Pereira de Lima - São Paulo, 2018. 146 p.

Dissertação (Mestrado - Programa de Pós-Graduação em Direito Civil) Faculdade de Direito, Universidade de São Paulo, 2018.

1. direito do consumidor. 2. investidor. 3. mercado de capitais. 4. fundo de investimento. 5. Código de Defesa do Consumidor.

I. Lima, Cíntia Rosa Pereira de, orient. II. Título 
DAPHNE NORONHA HACHUL

PROTEÇÃO JURÍDICA DO INVESTIDOR-CONSUMIDOR

Dissertação apresentada à Faculdade de Direito da Universidade de São Paulo, como exigência parcial para obtenção do título de Mestre em Direito, na área de concentração Direito Civil, sob a orientação da Professora Associada Doutora Cíntia Rosa Pereira de Lima.

Banca Examinadora:

Prof. Dr.

Instituição:

Julgamento:

Assinatura

Prof. Dr.

Instituição:

Julgamento:

Assinatura

Prof. Dr.

Instituição:

Julgamento:

Assinatura:

UNIVERSIDADE DE SÃO PAULO

FACULDADE DE DIREITO

São Paulo-SP 
Ao meu amor, Renato Losinskas Hachul, meu alento, meu porto seguro e minha coragem, por tudo que representa na minha vida. 


\section{AGRADECIMENTOS}

À minha família pela insistência na continuidade dos estudos, em especial à minha mãe, pela demonstração de força e fé, mesmos nos momentos mais difíceis.

Ao meu querido marido, Renato Losinskas Hachul, que suportou todas as minhas angústias e momentos conturbados, por sempre acreditar nos meus objetivos e sonhos, pelas considerações e auxílios na discussão sobre o tema.

À Professora Cíntia Rosa Pereira de Lima, pela oportunidade de estar sob a sua orientação, por acreditar no tema e pelas fundamentais considerações e contribuições ao desenvolvimento da presente dissertação, bem como por todos os momentos alegres e desafiadores vividos.

Ao Professor Rui Geraldo Camargo Viana, acadêmico e profissional do Direito admirável e inspirador, pelo apoio e incentivo à vida acadêmica.

Aos amigos e companheiros de mestrado, Caroline Narvaez Leite e Wévertton Gabriel Gomes Flumignan, por compartilharem seus conhecimentos jurídicos, pelas experiências trocadas, pela força e pelo apoio constante e, em especial à Lívia Forner Moreno Ramiro, que se tornou uma grande amiga, pela força constante para a conclusão da dissertação. Sem eles o caminho no mestrado não teria sido tão gratificante e enriquecedor.

Às amigas queridas da Faculdade de Direito da Universidade Presbiteriana Mackenzie pelo constante apoio, considerações e incentivos à finalização da dissertação. 


\section{RESUMO}

HACHUL, Daphne Noronha. Proteção jurídica do investidor-consumidor. 146 p. Dissertação (Mestrado em Direito) - Faculdade de Direito, Universidade de São Paulo, São Paulo, 2018.

O presente estudo tem como objeto a proteção jurídica do investidor no mercado de capitais. Para tanto, é analisada qual a tutela mais adequada para a defesa de seus direitos, conforme as correntes doutrinárias e a evolução do entendimento jurisprudencial. Foi abordado o arcabouço jurídico do mercado financeiro, em especial do mercado de capitais, bem como a esfera jurídico-contratual do investidor como consumidor, para identificar como a extensão dos direitos e garantias fundamentais nas relações privadas atingem as relações contratuais do mercado de capitais, em especial nas relações que envolvem os fundos de investimento. Um aspecto importante do estudo é o desenvolvimento do conceito de investidor-consumidor e a aplicabilidade do Código de Defesa do Consumidor para as relações entre investidores e as instituições financeiras do mercado de capitais. Ainda, para compreender de que forma o investidor encontra-se protegido no mercado, foram abordados os direitos da informação adequada, transparência, liberdade de escolha, noção de risco do investimento realizado, proibição publicidade enganosa e abusiva e a de garantia de rendimento, bem como direito à efetiva prevenção e reparação de danos patrimoniais e morais, individual e coletivamente. Por fim, foram analisados os julgamentos de casos concretos pelo Superior Tribunal de Justiça, a fim de verificar o entendimento emanado pela Corte Superior sobre a aplicabilidade do Código de Defesa do Consumidor às relações contratuais no mercado de capitais, identificando a tutela reparatória que vem sendo aplicada, e demonstradas as dificuldades e os desafios em se garantir uma efetiva proteção do investidor-consumidor no atual cenário do arcabouço jurídico do mercado de capitais.

Palavras-chave: consumidor - investidor - mercado de capitais - fundo de investimento - Código de Defesa do Consumidor 


\begin{abstract}
HACHUL, Daphne Noronha. The legal protection of the investor-consumer. $146 \mathrm{p}$. Dissertação (Mestrado em Direito) - Faculdade de Direito, Universidade de São Paulo, São Paulo, 2018.

This paper will study the legal protection of the investor in the capital market. To do so, will be analyzed what is the most appropriate tutelage for a defense of their rights, according to doctrinal currents and jurisprudential understanding. It will analyses the capital market framework, as well as the legal-contractual sphere of investors as a consumer, to identify how the extension of the fundamental rights and guarantees in private relations acts in the contractual relations of the capital market, especially in relations involving the investment funds. An important aspect of the study is the development of the concept of investor and the application of the Consumer Defense Code for relations between investors and the financial institutions of the capital market. Also, to understand how the investor are proteceted, will addressed the legal rights of appropriate information, transparency, free choice, notion of risk with work, prohibition of misleading and abusive advertising, prohibition of results guarantee, and the right to effective prevention and redress of pecuniary and moral damages, individually and collectively. Finally, will be analysed the judgments of specific cases by the High Court of Justice, an end to verify the understanding issued by the High Court on an application of the Consumer Defense Code in contractual relations in the capital market, identifying the difficulties and challenges in guaranteeing an effective protection of the investor-consumer in the current scenario of the legal framework of the capital market.
\end{abstract}

Keywords: consumer - investor - capital market - investment fund - Consumer Protection Code 


\section{SUMÁRIO}

INTRODUÇÃO.

\section{A DEFESA DO CONSUMIDOR E O MERCADO DE CAPITAIS}

1.1. Da ordem econômica na Constituição Federal e a defesa do consumidor.

1.2. Organização e funcionamento do mercado de capitais: aspectos necessários para a compreensão do tema

1.2.1. O mercado de capitais como segmento do mercado financeiro: conceitos, natureza jurídica e funções.

1.2.2. Agentes do mercado de capitais no Brasil.......................................23

1.2.3. Os valores mobiliários e os fundos de investimento...........................36

\section{O CONSUMIDOR NO MERCADO DE CAPITAIS}

2.1. Os sujeitos na relação de consumo no mercado de capitais

2.1.1. O conceito jurídico de investidor como consumidor.

2.1.2. O conceito jurídico de fornecedor na relação de consumo de investimentos

2.2. O objeto e a remuneração dos fornecedores na relação de consumo de investimentos .50

2.3. Todo investidor pode ser considerado consumidor no mercado de capitais? .56

\section{OS CONTRATOS NO MERCADO DE CAPITAIS}

3.1. A crise dos contratos e a sua massificação: a absorção do contrato de adesão pelos mercados financeiro e de capitais.

3.2. A função social, a boa-fé objetiva e a necessidade de equilíbrio nas relações contratuais no mercado de capitais. 68

3.3. A aproximação principiológica entre o Código de Defesa do Consumidor e o Código Civil: o diálogo das fontes aplicado ao mercado financeiro e de capitais .75 
3.4. O contrato no fundo de investimento e a sua natureza jurídica.

4. TUTELA JURÍDICA DO INVESTIDOR-CONSUMIDOR DISCIPLINADA PELO CÓDIGO DE DEFESA DO CONSUMIDOR E PELA REGULAÇÃO E AUTORREGULAÇÃO DO MERCADO DE CAPITAIS: PRINCIPAIS DIREITOS PROTETIVOS APLICÁVEIS AO INVESTIDOR-CONSUMIDOR

4.1. A informação adequada e a transparência 89

4.2. A liberdade de escolha e a igualdade nas contratações, a noção de risco e do investimento realizado 100

4.3. A proibição de publicidade enganosa e abusiva e de garantia de rendimento 106

4.4. A adequação do investimento ao perfil do investidor (suitability) 110

4.5. A reparação individual e coletiva por danos materiais e morais 115

5. OS DESAFIOS DA PROTEÇÃO JURÍDICA DO INVESTIDOR-CONSUMIDOR NO MERCADO DE CAPITAIS

5.1. As proposições do Superior Tribunal de Justiça sobre o investidor-consumidor no mercado de capitais. 122

5.2. Breves considerações sobre as dificuldades e desafios na efetivação das normas protetivas do investidor-consumidor. 128

CONCLUSÃO 132

REFERÊNCIAS 135 


\section{INTRODUÇÃO}

A relação jurídica no mercado de capitais, em especial nos fundos de investimentos, e os direitos protetivos do investidor, é matéria que tem avançado na doutrina e na jurisprudência no Brasil.

O mercado de capitais representa uma das principais alavancas de desenvolvimento da economia de um país, porém, no Brasil, a tradição ainda é de desestímulo à aplicação em renda variável, em virtude da vulnerabilidade do setor, o qual depende de serviços e agentes especializados, garantia de informação clara e transparência, bem como de legislação complexa para evitar violações e abusos de direito.

Como o mercado de valores mobiliários e o número de investidores avança, especialmente aqueles eventuais, ou seja, não profissionais ou qualificados, assume-se cada vez mais a importância da intervenção do Direito, a fim de se sistematizar as regras necessárias para assegurar o equilíbrio das funções das instituições financeiras e dos agentes do mercado de capitais, com o bem-estar social.

A atualidade do tema e sua importância decorrem, ainda, da evidente massificação das relações contratuais, com a necessidade de se fazerem presentes princípios sociais como o da função social do contrato, da boa-fé objetiva e do equilíbrio contratual.

O enfrentamento da proteção do investidor, além disso, decorre também da necessidade de se desenvolver e buscar efetivamente o conceito de investidor como consumidor, e entender a tutela mais adequada para a defesa de seus direitos, conforme as correntes doutrinárias e a evolução do entendimento jurisprudencial.

O estudo do arcabouço jurídico do mercado financeiro, em especial do mercado de capitais, bem como da esfera jurídico-contratual do investidor como consumidor, representa identificar como a extensão dos direitos e garantias fundamentais nas relações privadas atingem as relações contratuais do mercado de capitais, em especial nas relações que envolvem os fundos de investimento.

Para a compressão da tutela jurídica do investidor-consumidor analisou-se institutos como a informação adequada, a transparência, a liberdade de escolha, a 
noção de risco e do investimento realizado, a proibição publicidade enganosa e abusiva e a de garantia de rendimento, bem como direito à efetiva prevenção e reparação de danos patrimoniais e morais, individual e coletivamente.

Estruturou-se a realidade da proteção administrativa, civil e consumerista do investidor no Brasil, destacando o seu tratamento especial, por meio da identificação dos institutos protetivos materiais voltados para o investidor do mercado de capitais, representando o presente estudo em uma conscientização do mercado de capitais, representado pelos diversos intermediários financeiros e profissionais do setor, em garantirem e respeitarem tais institutos ética, contratual e normativamente.

A preocupação com uma ordem econômica-social e com o equilíbrio nas relações contratuais, em especial aquelas cujo objeto trata de conceitos técnicos e específicos, impõe considerar, em determinadas situações, o investidor como vulnerável e sujeito de proteção como consumidor.

A complexidade do mercado de capitais e a especificidade da matéria dificultam a correta e justa aplicação dos direitos dos investidores nos casos concretos pelo Poder Judiciário, o que também impõe delimitar-se o arcabouço jurídico e as responsabilidades a serem impostas aos violares dos direitos de proteção dos investidores no mercado de capitais.

Para tanto, em primeiro lugar, destacou-se a proteção constitucional do consumidor, bem como delimitou-se o regime jurídico do mercado de capitais, o que permitiu a análise dos agentes e dos serviços financeiros voltados para os investimentos.

No momento subsequente, desenvolveu-se o conceito de investidor como consumidor e a relação de consumo existente com os fornecedores intermediários financeiros, bem como delimitou-se a esfera jurídico-contratual aplicada ao investidor no mercado de capitais, mediante análise dos princípios gerais contratuais e os contratos de fundos de investimentos e sua natureza jurídica, destacando a possibilidade de aplicação da teoria do diálogo das fontes na solução dos casos concretos envolvendo essas relações especiais de consumo.

O passo seguinte foi de analisar os principais direitos protetivos do investidor no mercado de capitais previstos no Código de Defesa do Consumidor, bem como na regulação e na autorregulação. 
Por fim, foram analisados os julgamentos de casos concretos pelo Superior Tribunal de Justiça, a fim de verificar o entendimento emanado pela Corte Superior sobre a aplicabilidade do Código de Defesa do Consumidor às relações contratuais no mercado de capitais, identificando a tutela reparatória que vem sendo aplicada, e demonstradas as dificuldades e os desafios em se garantir uma efetiva proteção do investidor-consumidor no atual cenário do arcabouço jurídico do mercado de capitais.

A observância dos institutos de proteção do investidor como consumidor, refletirão, embora sujeitos aos riscos de tal mercado, no aumento da confiança do investidor no mercado de capitais.

Diante disso, acreditando na interação entre as fontes do direito e na necessidade de estruturação do arcabouço jurídico que envolve o mercado de capitais, sistematiza-se no presente estudo a compreensão do investidor como consumidor e sujeito de direitos, contribuindo para discussões futuras sobre a proteção do investidor no mencionado setor, em especial no sentido de que a legislação incidente se torne mais acessível e de melhor compreensão do funcionamento, dos deveres, das obrigações e dos direitos dos agentes do mercado de capitais, de modo a garantir um eficiente acesso do investidorconsumidor ao mercado de capitais e a garantia de uma tutela preventiva e reparatória. 


\section{CONCLUSÃO}

Conclui-se, de toda a pesquisa empreendida e de todo o exposto na presente dissertação, que há hipóteses em que o investidor é consumidor na acepção do artigo $2^{\circ}$ do Código de Defesa do Consumidor, vez que os serviços que adquire como destinatário final no mercado de capitais está compreendido no gênero "serviço financeiro".

Entende-se, ainda, que embora os investidores profissionais e qualificados elencados na Instrução Normativa da CVM no 555/2014, em regra, não sejam consumidores, quando se tratar das hipóteses de investidores denominados profissionais, as pessoas naturais ou jurídicas que possuam investimentos financeiros em valor superior a $\mathrm{R} \$ 10.000 .000,00$ (dez milhões de reais) e que, adicionalmente, atestem por escrito sua condição de investidor profissional mediante termo próprio (inciso IV, artigo 9-A da IN no 555/2014 da CVM); e os denominados qualificados, as pessoas naturais ou jurídicas que possuam investimentos financeiros em valor superior a $R \$ 1.000 .000,00$ (um milhão de reais) e que, adicionalmente, atestem por escrito sua condição de investidor qualificado mediante termo próprio (inciso II, do artigo 9--B da IN nํ555/2014 da CVM), estes sim devem ser considerados consumidores, vez que o valor aplicado não Ihes retira a condição de vulnerabilidade em todas as suas vertentes e de hipossuficiência frente aos intermediários financeiros.

No caso dos fundos de investimentos, especificamente, ainda que o investidor seja um cotista do fundo, conclui-se que se trata de investidorconsumidor, vez que está em uma posição de vulnerabilidade frente a especificidade dos serviços prestados pelos intermediários financeiros, como também em virtude da atuação dos intermediários financeiros como fornecedores de serviços (distribuidoras, administradores e gestores dos fundos de investimento), incidindo todas as normas protetivas do Código de Defesa do Consumidor. No mesmo sentido, se entende sobre a relação entre investidorconsumidor e as corretoras de valores mobiliários na compra e venda ações e outros ativos. 
Acerca da proteção jurídica do investidor-consumidor no mercado de capitais, em especial, nas aplicações em fundos de investimentos vem sendo delimitada e garantida pelos órgãos reguladores, bem como pela autorregulação, mas a proteção efetiva de seus direitos ocorre pela aplicação dos direitos do consumidor na relação jurídica no mercado de capitais.

A defesa do consumidor como princípio de desenvolvimento econômico, deve ser atendida pela ordem econômica e as funções dos diversos agentes econômicos atuantes no mercado de capitais são bem definidas pela legislação incidente, bem como a Comissão de Valores Mobiliários define categorias de investidores conforme a sofisticação do investidor, alinhado com o desenvolvimento das práticas de suitability, implicando na proibição da aquisição e/ou negociação de determinados produtos por investidores com capacidade financeira limitada, bem como na diferenciação das informações divulgadas sobre produtos destinados a investidores de maior sofisticação, criando diferentes regimes informacionais, categorizando os tipos de investidores de modo que a aplicação do Código de Defesa do Consumidor não independe, na sua totalidade, de tal classificação.

A esfera jurídico-contratual aplicada ao investidor no mercado de capitais é a dos contratos de adesão, com incidência de todos os princípios gerais contratuais, como a função social do contrato e a boa-fé objetiva, ou seja, incide tanto as normas de Direito Civil, como as Direito do Consumidor, com a possibilidade de aplicação da teoria do diálogo das fontes para a solução de casos concretos, em razão da incidência das normas específicas do mercado de capitais. No caso dos fundos de investimento verificou-se que se trata de um contrato de adesão com natureza jurídica de condomínio especial.

A tutela jurídica do investidor-consumidor ocorre, principalmente, pela necessidade de observância dos direitos à informação adequada prestada e veiculada e à transparência, à liberdade de escolha, à noção de risco e do investimento realizado, à proibição de publicidade enganosa e abusiva e a de garantia de rendimento do investimento realizado, à adequação dos investimentos ao perfil do investidor, bem como à efetiva prevenção e reparação de danos patrimoniais e morais, individual e coletivamente.

A complexidade do mercado de capitais e a especificidade da matéria dificultam a correta e justa aplicação dos direitos dos investidores nos casos 
concretos pelo Poder Judiciário, bem como a aferição de prejuízos materiais e morais, especialmente em razão da dificuldade das provas que devem ser realizadas para constatar o atendimento ou não pelo intermediário financeiro dos princípios básicos de tutela do investidor-consumidor como também se as eventuais perdas patrimoniais sofridas ocorreram por má-prestação dos serviços pelo fornecedor.

Os esforços dos órgãos reguladores e da autorregulação em tornar o mercado de capitais cada vez mais transparente e educar os profissionais habilitados e os investidores, demonstram a disposição dos agentes em garantir um mercado mais eficiente e seguro para os investidores. Contudo, os desafios ainda são muitos e a legislação esparsa dificulta uma melhor compreensão dos deveres, dos direitos e das responsabilidades incidentes nas relações contratuais no mercado de capitais no Brasil pelo investidor-consumidor.

Ao proteger o investidor-consumidor, entendendo ele como vulnerável frente aos complexos problemas e riscos do mercado de capitais, resguardados os limites de tal proteção e com a continuidade do empenho dos órgãos de regulação e autorregulação, bem como dos intermediários financeiros em agir ética e legalmente, refletirão no aumento da confiança do investidor no mercado de capitais, possibilitando seu desenvolvimento. 


\section{REFERÊNCIAS}

AGUIAR JUNIOR, Ruy Rosado. Aspectos dos fundos de investimento. In: MUSSI, Jorge; SALOMÃO, Luis Felipe; MAIA FILHO, Napoleão Nunes (org.). Estudos jurídicos em homenagem ao Ministro Cesar Asfor Rocha. Ribeirão Preto: Migalhas, 2012, v. 3.

ALVES, André Gomes de Sousa. Os Fundos de Investimento entre a Regulação Social do Mercado e a Proteção Jurídica do Investidor-Consumidor. Dissertação de Mestrado apresentada ao Programa de Pós-Graduação em Ciências Jurídicas da Universidade Federal da Paraíba - Mestrado. Área de Concentração: Direito Econômico. João Pessoa, 2011. Disponível em http://www.ccj.ufpb.br/pos/wpcontent/uploads/2013/07/Andre-Gomes-Fundos-de-Investimento-e-

Consumidor.pdf.

ALVIM, Arruda [et al.]. Código do Consumidor comentado. 2. ed. São Paulo: Revista dos Tribunais, 1995.

ASSOCIAÇÃO NACIONAL DAS CORRETORAS E DISTRIBUIDORAS DE TÍTULOS E VALORES MOBILIÁRIOS - http://www.ancord.org.br.

ASSAF NETO, Alexandre. Mercado Financeiro. 7ª ed. - São Paulo: Atlas, 2007.

ASSOCIAÇÃO BRASILEIRA DAS ENTIDADES DOS MERCADOS FINANCEIRO E DE CAPITAIS - www.anbima.com.br.

AZEVEDO, Álvaro Villaça. Teoria geral dos contratos típicos e atípicos. $2^{\underline{a}}$ ed., São Paulo: Atlas, 2004.

AZEVEDO, Antonio Junqueira de. O Direito pós-moderno e a codificação. Revista Direito do Consumidor, São Paulo, 2002, v. 33, p. 124 e ss. 
- Insuficiências, deficiências e desatualização do projeto de código civil na questão da boa-fé objetiva nos contratos. Revista Trimestral de Direito Civil, Rio de Janeiro, v. 1, n. jan/mar. 2000, p. 03-12.

; TÔRRES, Heleno Taveira; CARBONE, Paolo (coord.) - Princípios do Novo Código Civil Brasileiro e Outros Temas - Homenagem a Tullio Ascarelli. - São Paulo, Quartier Latin, 2008.

. Princípios do novo direito contratual e desregulamentação do mercado Direito de exclusividade nas relações contratuais de fornecimento - Função social do contrato e responsabilidade aquiliana do terceiro que contribui para 0 inadimplemento contratual. Revista dos Tribunais, São Paulo, ano 87, v. 750, abril 1998, p. 113-120.

BM\&FBOVESPA - www.bmfbovespa.com.br.

BANCO CENTRAL DO BRASIL - www.bcb.gov.br.

BENJAMIN, Antônio Herman V.; MARQUES, Claudia Lima; e BESSA, Leonardo Roscoe. Manual de Direito do Consumidor. $4^{\mathrm{a}}$ ed. - São Paulo: Revista dos Tribunais, 2012.

- O conceito jurídico de consumidor. In Claudia Lima Marques e Bruno Miragem (organizadores). Direito do Consumidor: Fundamentos do Direito do Consumidor (Coleção doutrinas essenciais, direito do consumidor, vol. I) - São Paulo: Revista dos Tribunais, 2011 (original em Revista de Direito do Consumidor, RDC 75/43, jul.-set./2010), p. 935-954.

BESSA, Leonardo Roscoe. Fornecedor equiparado. In Claudia Lima Marques e Bruno Miragem (organizadores). Direito do Consumidor: Fundamentos do Direito do Consumidor (Coleção doutrinas essenciais, direito do consumidor, vol. I) - São Paulo: Revista dos Tribunais, 2011 (original em Revista do Direito do Consumidor, RDC 61/126, jan.mar/2007), p. 1.011-1029. 
BOURGOIGNIE, Thierry. O conceito jurídico de consumidor. In Claudia Lima Marques e Bruno Miragem (organizadores). Direito do Consumidor: Fundamentos do Direito do Consumidor (Coleção doutrinas essenciais, direito do consumidor, vol. I). São Paulo: Revista dos Tribunais, 2011 (original em Revista do Direito do Consumidor, RDC 2/7, abr.-jun./1992), p. 1.055-1.106.

BRANCO, Gerson Luiz Carlos. Função social dos contratos: interpretação à luz do Código Civil. São Paulo: Saraiva, 2009.

CAGGJANO, Mônica Herman Salem. Código do Consumidor - aspectos constitucionais. In Cláudia Lima Marques e Bruno Miragem (organizadores). Direito do Consumidor: vulnerabilidade do consumidor e modelos de proteção (Coleção doutrinas essenciais, direito do consumidor, vol. II) - São Paulo: Revista dos Tribunais, 2011 (original em Revista dos Tribunais, RT 666/58, abr./1191), p. 363389.

CARVALHO, Mário Tavernard Martins de. Regime jurídico dos fundos de investimentos. São Paulo: Quartier Latin, 2012.

CAVALIERI FILHO, Sergio. Programa de Responsabilidade Civil. 5a ed. - São Paulo: Malheiros, 2004.

COELHO, Fábio Ulhôa. A responsabilidade civil dos administradores de instituições financeiras. In Aspectos atuais do mercado financeiro e de capitais. Roberto Quiroga Mosquera (coordenador). - São Paulo: Dialética, 1999, p. 83-112.

COMISSÃO DE VALORES MOBILIÁRIOS - www.cvm.gov.br.

Fundos de investimento, Cadernos CVM, 3. Rio de Janeiro: Comissão de Valores Mobiliários, 2014.2 Disponível em: http://www.portaldoinvestidor.gov.br/portaldoinvestidor/export/sites/portaldoinvesti dor/publicacao/Cadernos/CVM-Caderno-3.pdf. 
. O mercado de valores mobiliários brasileiro. $3^{\underline{a}}$ ed. Rio de Janeiro: Comissão de Valores Mobiliários, 2014. Disponível em http://www.investidor.gov.br/portaldoinvestidor/export/sites/portaldoinvestidor/publi cacao/Livro/LivroTOP-CVM.pdf.

Direito do mercado de valores mobiliários. $1^{1 \stackrel{a}{ }}$ ed. Rio de Janeiro: Comissão de Valores Mobiliários, 2017, p. 304. Disponível em http://www.investidor.gov.br/portaldoinvestidor/export/sites/portaldoinvestidor/publi cacao/Livro/Livro_top_Direito.pdf.

COMPARATO, Fábio Konder. A proteção ao consumidor na Constituição brasileira de 1988. In Cláudia Lima Marques e Bruno Miragem (organizadores). Direito do Consumidor: vulnerabilidade do consumidor e modelos de proteção (Coleção doutrinas essenciais, direito do consumidor, vol. II) - São Paulo: Revista dos Tribunais, 2011 (original em Revista de Direito Mercantil, RDM 80/66, out.dez./1990), p. 175-176.

DALL'AGNOL Jr., Antônio Janyr. Direito do consumidor e serviços bancários e financeiros - aplicação do CDC nas atividades bancárias. Revista do Direito do Consumidor, São Paulo: Revista dos Tribunais, v. 27, jul./set. 1996, p. 07-17.

DE LUCCA, Newton. Direito do Consumidor - Teoria Geral da Relação Jurídica de Consumo. $2^{2}$ ed. - São Paulo: Quartier Latin, 2008.

As bolsas de valores e os valores mobiliários. Revista do Tribunal Regional Federal da 3ª Região, n. 35, São Paulo, jul. 1998, p. 19-38.

A responsabilidade civil dos administradores das instituições financeiras. Revista de Direito Mercantil, Industrial, Econômico e Financeiro, São Paulo, v. 26, n. 67, p. 32-38, jul.-set. 1987. 
DONNINI, Rogério Ferraz. A Constituição Federal e a concepção social do contrato. In VIANA, Rui Geraldo Camargo; NERY, Rosa Maria de Andrade (orgs.). Temas atuais de direito civil na Constituição Federal. São Paulo: Revista dos Tribunais, 2000, p. 69-79.

EFING, Antonio Carlos. Contratos e procedimentos bancários à luz do código de defesa do consumidor. $1^{\underline{a}}$ ed., $3^{\underline{a}}$ tir. - São Paulo: Revista dos Tribunais, 2000 (biblioteca de direito do consumidor; v. 12).

- Responsabilidade civil do agente bancário e financeiro, segundo as normas do Código de Defesa do Consumidor. Revista de Direito do Consumidor, São Paulo, n. 18, abr.-jun./1996, p.105-124.

. Sistema financeiro e o Código do Consumidor: análise conceitual quanto à incidência das normas do sistema de defesa do consumidor aos contratos bancários e financeiros. Revista de Direito do Consumidor, São Paulo: Editora Revista dos Tribunais, n. 17, jan.-mar./1996, p. 65-84.

EIZIRIK, Nelson. Temas de Direito Societário. Rio de Janeiro: Renovar, 2005. ; GAAL, Ariádna B.; PARENTE, Flávia; HENRIQUES, Marcus de Freitas. Mercado de Capitais: regime jurídico. 2. ed., Rio de Janeiro: Renovar, 2008.

FILOMENO, José Geraldo Brito. Manual de Direitos do Consumidor. $8^{\mathrm{a}}$ ed. - São Paulo: Atlas, 2005.

FORTUNA, Eduardo. Mercado financeiro: produtos e serviços. 19a ed. - Rio de Janeiro: Qualitymark Editora, 2013.

FREITAS, Ricardo de Santos. Responsabilidade civil dos administradores de fundos de investimento. In Aspectos atuais do mercado financeiro e de capitais. Roberto Quiroga Mosquera (coordenador). - São Paulo: Dialética, 1999. 
FRITZ, Karina Nunes. A responsabilidade dos bancos por falhas na informação em investimentos de capital: uma análise comparada com o direito alemão. Revista de Direito Civil Contemporâneo, vol. 8/2016 | p. 167 - 200 | Jul - Set / 2016, Revista dos Tribunais Online: Thomson Reuters.

GAGGINI, Fernando Schwarz. Fundos de investimento no direito brasileiro. São Paulo: Livraria e editora universitária de direito, 2001.

GODOY, Claudio Luiz Bueno de. Função Social do Contrato: os novos princípios contratuais. $4^{\mathrm{a}}$ ed. - São Paulo: Saraiva, 2012.

GOMES, Orlando. Responsabilidade Civil. Rio de Janeiro: Forense, 2011.

. Contratos. 25a ed. - Rio de Janeiro: Forense, 2002.

. Os direitos dos consumidores. In Claudia Lima Marques e Bruno Miragem (organizadores). Direito do Consumidor: Vulnerabilidade do Consumidor e Modelos de Proteção (Coleção doutrinas essenciais, direito do consumidor, vol. II) - São Paulo: Revista dos Tribunais, 2011 (original em Revista de Direito do Consumidor, RDC 77/19, jan.-març./2011), p. 1.001-1.008.

GRAU, Eros Roberto. A Ordem Econômica na Constituição de 1988. 13ª ed. - São Paulo: Malheiros, 2008.

GRINOVER, Ada Pellegrini; BENJAMIN, Antonio Herman de Vasconcellos e; FINK, Daniel Roberto; FILOMENO, José Geraldo Brito; WATANABE, Kazuo; JÚNIOR, Nelson Nery; DENARI, Zelmo. Código de Defesa do Consumidor comentado pelos autores do anteprojeto. 10ª ed. Rio de Janeiro: Forense Universitária, 2011.

HIRONAKA, Giselda Maria Fernandes Novaes. Função social do contrato. Estudos Jurídicos. Estudos Jurídicos, v. 19, n. 47, 1986, p. 95-111. 
Contrato: estrutura milenar de fundação do direito privado. Revista do

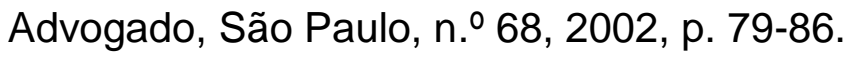

INTERNATIONAL ORGANIZATION OF SECURITIES COMMISSIONS - Objetivos e Princípios do Regulamento de Valores Mobiliários. Disponível em: https://www.iosco.org/library/pubdocs/pdf/IOSCOPD561.pdf.

KÜMPEL, Siegfried. Direito do Mercado de Capitais. Rio de Janeiro: Renovar, 2007. A proteção do consumidor no direito bancário e no direito do mercado de capitais. In Claudia Lima Marques e Bruno Miragem (organizadores). Direito do Consumidor: Fundamentos do Direito do Consumidor (Coleção doutrinas essenciais, direito do consumidor, vol. I) - São Paulo: Revista dos Tribunais, 2011 (original em Revista de Direito do Consumidor, RDC 52/319, out.-dez./2004), p. 853-884.

LEÃES, Luis Gastão Paes de Barros. A responsabilidade do fabricante pelo fato do produto. São Paulo: Saraiva, 1987.

LIMA, Cíntia Rosa Pereira de. Da aplicação do Código De Defesa do Consumidor às Instituições Financeiras. Revista da Faculdade de Direito da Universidade de São Paulo, vol. 101, jan./dez., 2006, p. 653-696.

A inversão do ônus da prova no Código de Defesa do Consumidor. Revista de Direito do Consumidor, São Paulo: Revista dos Tribunais, vol. 47, 2003, p. 200231.

LOPEZ, Teresa Ancona. Princípio da precaução e evolução da responsabilidade Civil. São Paulo: Quartier Latin, 2010.

; LEMOS, Patrícia Fava Iglecias; RODRIGUES JUNIOR, Otavio Luiz (coords.). Sociedade de Risco e Direito Privado: desafios normativos, consumeristas e ambientais. Apresentação. - São Paulo: Altas, 2013. 
MACEDO JÚNIOR, Ronaldo Porto. Contratos relacionais e defesa do consumidor. $2^{2}$ ed., São Paulo: Revista dos Tribunais, 2007.

. Privacidade, Mercado e Informação, in Revista de Direito do Consumidor, São Paulo: Editora Revista dos Tribunais, vol. 31, 1999, p. 13-24.

MANCUSO, Rodolfo de Camargo. Manual do Consumidor em Juízo. 4. ed. São Paulo: Saraiva, 2007.

MARQUES, Cláudia Lima. Contratos no código de defesa do consumidor: o novo regime das relações contratuais. 4. a ed. São Paulo: Revista dos Tribunais, 2002.

. Contratos no código de defesa do consumidor: o novo regime das relações contratuais. 3 ed.. São Paulo: Revista dos Tribunais, 1998.

. coordenação. Diálogo das Fontes: do conflito à coordenação de normas do direito brasileiro. São Paulo: Editora Revista dos Tribunais, 2012.

. Superação das Antinomias pelo Diálogo das Fontes: o modelo brasileiro de coexistência entre o Código de Defesa do Consumidor e o Código Civil de 2002 - reflexões sobre a necessária visão do relacionamento entre o CDC e CC/2002. In JUNQUEIRA DE AZEVEDO, Antonio; TÔRRES, Heleno Taveira; CARBONE, Paolo (coord.) - Princípios do Novo Código Civil Brasileiro e Outros Temas Homenagem a Tullio Ascarelli. - São Paulo: Quartier Latin, 2008.

; ALMEIDA, João Batista de; PFEIFFER, Roberto Augusto Castellanos (coord.). Aplicação do Código de Defesa do Consumidor aos Bancos. São Paulo: Revista dos Tribunais, 2006.

MARINS, James. A responsabilidade da empresa pelo fato do produto: os acidentes de consumo do Código de Proteção ao Direito do Consumidor. São Paulo: Revista dos Tribunais, 1993. 
Proteção contratual do CDC a contratos interempresariais, inclusive bancários. Revista de Direito do Consumidor, São Paulo, v. 18, p. 94-104, abr./jun. de 1996.

et al.. Código do Consumidor comentado. São Paulo: Revista dos Tribunais, 1991.

MIRAGEM, Bruno. O direito do consumidor como direito fundamental. In Cláudia Lima Marques e Bruno Miragem (organizadores). Direito do Consumidor: vulnerabilidade do consumidor e modelos de proteção (Coleção doutrinas essenciais, direito do consumidor, vol. II) - São Paulo: Revista dos Tribunais, 2011 (original em Revista de Direito do Consumidor, RDC 43/111, jul.-set./2002).

MOSQUEIRA, Roberto Quiroga. Os princípios informadores do Direito do Mercado Financeiro e de Capitais. In Aspectos atuais do direito do mercado financeiro e de capitais. São Paulo: Dialética, 1999.

NERY JÚNIOR, Nelson. Constituição Federal comentada e legislação constitucional. 4⿳亠丷a ed., São Paulo: Revista dos Tribunais, 2013.

NUNES, Luis Antonio Rizzatto. Curso de direito do consumidor. 4. ed. São Paulo: Saraiva, 2009.

NUSDEO, Fábio. Curso de Economia: introdução ao direito econômico. São Paulo: Revista dos Tribunais, 2005.

PASQUALOTTO, Adalberto. Conceitos fundamentais do Código de Defesa do Consumidor. In Claudia Lima Marques e Bruno Miragem (organizadores). Direito do Consumidor: Fundamentos do Direito do Consumidor (Coleção doutrinas essenciais, direito do consumidor, vol. I) - São Paulo: Revista dos Tribunais, 2011 (original em Revista dos Tribunais, RT 666/48, abr./1991), p. 61-73. 
PETTER, Lafayete Josué. Princípios Constitucionais da Ordem Econômica: o significado e o alcance do art. 170 da Constituição Federal. 2. ed. São Paulo: Revista dos Tribunais, 2008.

PFEIFFER, Roberto Augusto Castellanos. Defesa da Concorrência e Bem-Estar do Consumidor. Tese de Doutorado apresentada à Faculdade de Direito da Universidade de São Paulo, 2010.

Aplicação do Código de Defesa do Consumidor aos serviços bancários. In Claudia Lima Marques e Bruno Miragem (organizadores). Direito do Consumidor: Fundamentos do Direito do Consumidor (Coleção doutrinas essenciais, direito do consumidor, vol. I) - São Paulo: Revista dos Tribunais, 2011 (original em Revista de Direito Bancário e do Mercado de Capitais, RDB 38/75, out.-dez./2007), p. 805834.

Aplicação do Código de Defesa dos Consumidores aos administradores de fundos de investimento. Revista de Direito do Consumidor, v. 16, n. 61, jan.mar./2007, São Paulo : Revista dos Tribunais, p. 190-202.

. Comentário Doutrinário. 3.1. Contrato Bancário (Recurso Especial n. 656.932-SP (2004/0011451-0). Revista do Superior Tribunal de Justiça, vol. 240, Tomo 1, ano 27, outubro/novembro/dezembro de 2015, Brasília: STJ, p. 301-329.

PONTES DE MIRANDA, Francisco Cavalcanti. Tratado de Direito Privado: parte especial, v. 51, São Paulo: Revista dos Tribunais, 1985.

PORTAL DO INVESTIDOR - www.portaldoinvestidor.gov.br.

QUEIROZ, José Eduardo Carneiro. O conceito de valor mobiliário e a competência da comissão de valores mobiliários e do Banco Central do Brasil. In Aspectos atuais do mercado financeiro e de capitais. Roberto Quiroga Mosquera (coordenador). São Paulo: Dialética, 1999, p. 129-135. 
ROCHA, Tatiana Nogueira da. Fundos de investimento e o papel do administrador. São Paulo: Textonovo, 2003.

ROPPO, Enzo. O Contrato. Tradução de Ana Coimbra e Manuel Januário Costa Gomes. Coimbra: Almedina, 1988.

RUY, Fernando Estevam Bravin. Direito do Investidor Consumidor no Mercado de Capitais e nos Fundos de Investimento. Rio de Janeiro: Lumen Juris, 2010

SANSEVERINO, Paulo de Tarso Vieira. Responsabilidade Civil no Código do Consumidor e a defesa do fornecedor. 3 ed. - São Paulo: Saraiva, 2010.

SANTIAGO, Mariana Ribeiro. O princípio da função social do contrato. Curitiba: Juruá, 2005.

SILVA, Marcus Vinicius Fernandes Andrade da. O Direito do Consumidor e a Publicidade. São Paulo: MP, 2008.

SOUTO, Marcos Juruena Villela. Direito Administrativo da Economia. $3^{\text {a }}$ ed. - São Paulo: Lumen Juris, 2003.

SOUZA, Washington Peluso Albino de. Considerações a respeito do CDC. In Claudia Lima Marques e Bruno Miragem (organizadores). Direito do Consumidor: Fundamentos do Direito do Consumidor (Coleção doutrinas essenciais, direito do consumidor, vol. I) - São Paulo: Revista dos Tribunais, 2011 (original em Revista de Direito Civil, RDCiv 58/98, out.-dez./1991), p. 475-498.

STOCO, Rui. Tratado de Responsabilidade Civil. São Paulo: Revista dos Tribunais, 2004.

SUPERIOR TRIBUNAL DE JUSTIÇA - www.stj.jus.br. 
TARTUCE, Flávio. A teoria geral dos contratos de adesão no Código Civil. Visão a partir da teoria do diálogo das fontes. In: MARQUES, Claudia Lima (coord.). Diálogo das Fontes: do conflito à coordenação de normas do direito brasileiro. São Paulo: Revista dos Tribunais, 2012.

TURCZYN, Sidnei. O Sistema Financeiro Nacional e a Regulação Bancária. São Paulo: Editora Revista dos Tribunais, 2005.

WALD, Arnold. Alguns aspectos jurídicos da globalização financeira. In Aspectos atuais do mercado financeiro e de capitais. Roberto Quiroga Mosquera (coordenador). - São Paulo: Dialética, 1999, p. 09-18.

Da natureza jurídica do fundo imobiliário. Revista de Direito Mercantil, Industrial, Econômico e Financeiro, v. 80, out.- dez./1999 - São Paulo: Revista dos Tribunais.

. O direito do consumidor e suas repercussões em relação às instituições financeiras. Revista dos Tribunais, v. 666, abr. 1991, São Paulo: Revista dos Tribunais, p. 07-17.

O investidor qualificado no mercado de capitais brasileiro. Revista de Direito Bancário e do Mercado de Capitais, vol. 32. São Paulo: Revista dos Tribunais, 2006.

YAZBEK, Otavio. Regulação do mercado financeiro e de capitais. 2. ${ }^{\stackrel{a}{ }}$ ed., Rio de Janeiro: Elsevier, 2009.

ZACLIS, Lionel. Proteção coletiva dos investidores no mercado de capitais. - São Paulo: Revista dos Tribunais, 2007. 